\title{
PEMBUATAN ANTENA MIKROSTRIP MODEL ANGKA 4 UNTUK PENERIMA SINYAL TELEVISA PADA JALUR UHF (ULTRA HIGH FREKUENSI)
}

Oleh :

\author{
Lifwarda, Firdaus
}

Staf Pengajar Jurusan Teknik Elektro Politeknik Negeri Padang

\section{ABSTRACT}

Development of science and technology very rapidly in various fields brought great influence to all aspects of life one of this field of telecommunications. Development of telecommunication technology that bring due faster to hight public demand for telecommunications services users get an easy and fast service are used as medium convey information One of the device in question is antenna. Many type of antennas that have been developed for the reception of televisions signals and are generally made of wires, pipes or aluminium which has large size and weight. Needed for the antenna which has advantages in terms of shape light weight small volume from that can be easily adapted to the priimary device for on the fabrication and can be used for a wide band frequency. The antenna is microstrip antennas capable adjusted in assembly or in other words easily in a microstrip antenna placement. Microstrip antenna models 4 is designed to work in the range frequency $470-750 \mathrm{MHz}$. This antenna has a value of more than $-10 \mathrm{~dB}$ returnloss to a predetermined range frequency. The measurement results of the antenna resonates at a frequency of $518 \mathrm{MHz}$ gain value obtained by $1 \mathrm{~dB}$, and has a wide bandwidth of $7 \mathrm{MHz}$, while for polaradiasi shaped bidirectional.

Keywords : Mikrostrip 4 shape, IE3D, return loss, bandwidth, gain

\section{PENDAHULUAN}

Perkembangan ilmu pengetahuan dan teknologi yang sangat pesat diberbagai bidang membawa pengaruh yang sangat besar bagi seluruh aspek kehidupan, salah satunya dibidang telekomunikasi. Perkembangan dunia telekomunikasi beberapa tahun ini tumbuh dengan pesat. Dengan perkembangan zaman, alat telekomunikasi menjadi suatu sarana yang sangat dibutuhkan oleh masyarakat. Perkembangan teknologi telekomunikasi yang semakin cepat membawa akibat tingginya tuntutan masyarakat pengguna jasa telekomunikasi untuk mendapatkan layanan yang mudah dan cepat yang dimanfaatkan sebagai media dalam menyampaikan informasi.

Salah satu sistem telekomunikasi yang dimaksud terdiri dari perangkat tramsmitter dan receiver. Transmitter berfungsi membangkitkan sinyal RF. Setelah sinyal RF dibangkitkan selanjutnya diradiasikan melalui ruang bebas menuju receiver. Perangkat yang melakukan proses radiasi ini disebut Antena. Pada saat ini antena televisi UHF konvensional yang beredar memiliki ukuran yang relatif besar sehingga membutuhkan ruang penempatan yang besar. Agar tidak susah dalam penempatannya, maka perlu 
adanya antena yang berukuran kecil tetapi memiliki kinerja yang bagus.

Salah satu jenis antena yang memenuhi syarat tersebut adalah antena mikrostrip. Hal ini disebabkan karena antena mikrostrip sangat cocok digunakan untuk perangkat telekomunikasi yang sekarang ini sangat memperhatikan bentuk dan ukuran. Dapat dilihat dari segi bahan yang sederhana, bentuk, ukuran dan dimensi antenanya lebih kecil, harga produksi lebih murah dan mampu memberikan kinerja yang cukup baik. Antena mikrostrip mempunyai patch yang bermacam-macam seperti lingkaran, segitiga, cincin, segiempat dan model $\mathrm{H}$, L, E, O. Antena mikrostrip ini mampu disesuaikan dalam pemasangannya atau dengan kata lain antena mikrostrip lebih mudah dalam penempatannya.

Pada makalah ini dibuat antenna mikrostrip untuk penerima siaran TV indoor dengan bentuk angka empat dan melakukan uji kinerja serta membandingkannya dengan antenna penerima TV indoor konvensional

\section{TINJAUAN PUSTAKA}

\section{Antena Mikrostrip [1]}

Antena mikrostrip adalah salah satu jenis antena yang mempunyai bentuk seperti bilah/potongan yang mempunyai ukuran sangat tipis/kecil. Gambar 1. menunjukkan sruktur antena mikrostrip.

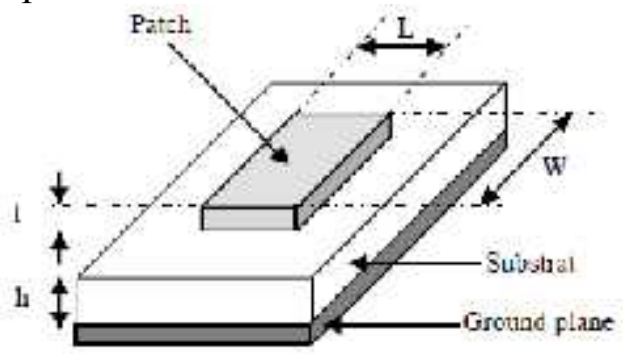

Gambar 1. Struktur Antena Mikrostrip

Tabel 1 Nilai Konstanta Dielektrik Beberapa Bahan Dielektrik

\begin{tabular}{|l|l|}
\hline Bahan dielektrik & $\begin{array}{l}\text { Nilai konstanta } \\
\text { dielektrik } \mathbf{(}_{\mathbf{r}} \mathbf{)}\end{array}$ \\
\hline Alumina & 9,8 \\
\hline $\begin{array}{l}\text { Material sistetik }- \\
\text { Teflon }\end{array}$ & 2,08 \\
\hline $\begin{array}{l}\text { Material komposit - } \\
\text { Duroid }\end{array}$ & $2,2-10,8$ \\
\hline $\begin{array}{l}\text { Ferimagnetik } \\
\text { Ferrite }\end{array}$ & $9-16$ \\
\hline $\begin{array}{l}\text { Semikonduktor } \\
\text { Silikon }\end{array}$ & 11,9 \\
\hline Fiberglass & 4,882 \\
\hline FR4_epoxy & 4,4 \\
\hline
\end{tabular}

Tabel 1 menunjukkan nilai permeativitas relatif bahan dielektrik yang sering digunakan untuk membuat substrat antena mikrostrip.

\section{Kelebihan dan Kekurangan Antena Mikrostrip}

Beberapa kelebihan dari antena mikrostrip adalah :

1. Mempunyai bobot yang ringan dan volume yang kecil.

2. Konfigurasi yang low profile sehingga bentuknya dapat disesuaikan dengan perangkat utamanya.

3. Biaya fabrikasi yang murah sehingga dapat dibuat dalam jumlah yang besar.

4. Mendukung polarisasi linear dan sirkular.

5. Dapat dengan mudah diintegrasikan dengan microwave integrated circuits (MICs)

6. Kemampuan dalam dual frequency dan triple frequency.

7. Tidak memerlukan catuan tambahan.

Namun, antena mikrostrip juga mempunyai beberapa kekurangan, yaitu :

1. Bandwidth yang sempit

2. Efisiensi yang rendah

3. Penguatan yang rendah 
4. Memiliki rugi-rugi hambatan (ohmic loss) pada pencatuan antena array

5. Memiliki daya (power) yang rendah

Timbulnya gelombang permukaan (surface wave)

\subsubsection{Teknik Pencatuan}

Antena mikrostrip dapat dicatu dengan beberapa metode. Metodemetode ini dapat diklasifikasikan ke dalam dua kategori, yaitu terhubung (contacting) dan tidak terhubung (noncontacting).

\subsubsection{Jenis-Jenis Antena mikrostrip}

Berdasarkan bentuk patch-nya antena mikrostrip terbagi menjadi :
a. Antena mikrostrip patch persegi panjang (rectangular)
b. Antena mikrostrip patch persegi (square)
c. Antena mikrostrip patch lingkaran (circular)
d. Antena mikrostrip patch elips (elliptical)
e. Antena mikrostrip patch segitiga (triangular)
f. Antena mikrostrip patch circular ring

Rumus teori untuk mencari patch persegi:

$$
W=\frac{c}{2 f_{0} \sqrt{\frac{\left(\varepsilon_{r}+1\right)}{2}}}
$$

\section{PERANCANGAN DAN PEMBUATAN ANTENA}

Antena yang diusulkan pada makalah ini ditunjukkan pada gambar 3.1. Ukuran tersebut disimulasikan dengan software IE3D dengan ukuran PCB double layer 1,6 mm dan konstanta dielektrik 4,7. Dan frekuensi kerja 450$750 \mathrm{MHz}$.

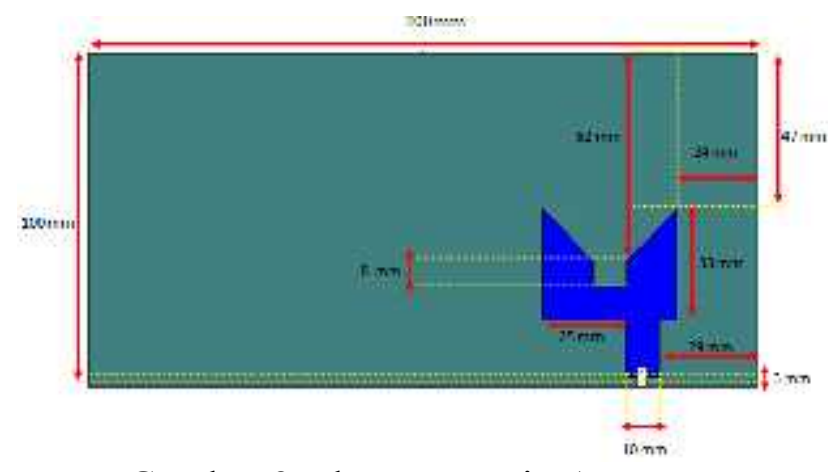

Gambar 2 Ukuran Desain Antena Model Angka 4

\section{HASIL DAN PEMBAHASAN}

Hasil simulasi hasil desain untuk return loss ditunjukkan pada gambar 3 return loss minimum dicapai pada frekuensi $775 \mathrm{MHz}$ sebesar $-27.5 \mathrm{~dB}$. Dengan bandwidth $500 \mathrm{MHz}$. Nilai return loss ini sudah cukup baik ini sudah sangat baik dari level yang disyaratkan sebesar-10B. VSWR maksimum pada simulasi ditunjukkan pada gambar 4. Terjadi pada frekuensi yang sama yaitu $775 \mathrm{MHz}$.

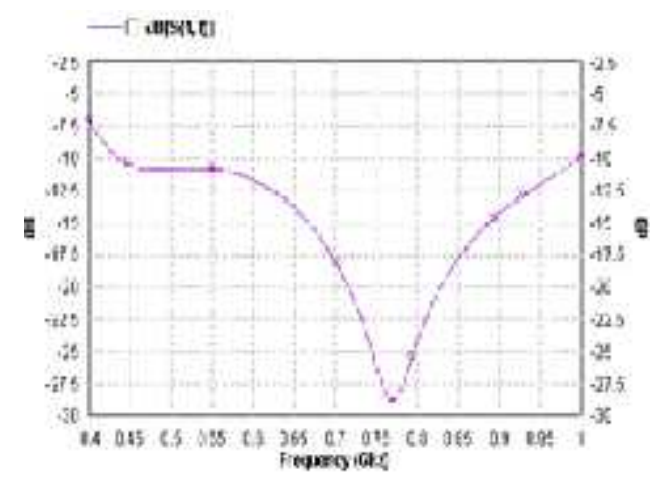

Gambar 3. Simulasi Return Loss antenna mikrostrip hasil desain.

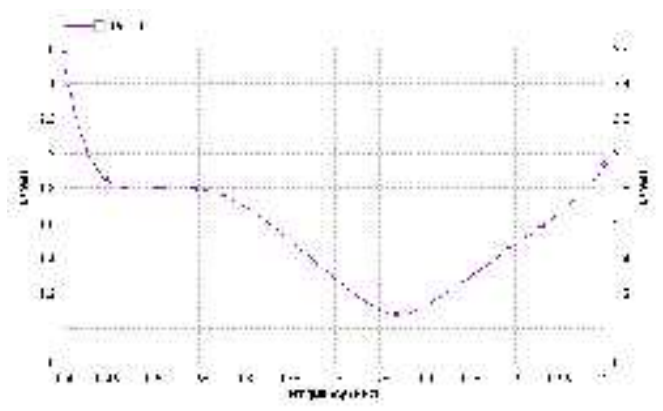

Gambar 4. Simulasi VSWR antenna hasil desain. 
Hasil fabrikasi antenna ditujukkan pada gambar 5. antenna dilengkapi konekt Male BNC selanjutnya antena diukur dan dibandingkan dengan dua buah antena konvensional jaguar 125 dan CNX 5000. Hasil pengukuran antenna ditunjukkan pada gambar 6. Dari gambar dapat dilihat polaradiasi antena adalah unidirectional. Dengan front to back ratio (FBR) $4 \mathrm{~dB}$. FBR ini lebih baik dibanding antena jaguar 125 dengan FBR 2 dB. Sedangkan untuk antena outdoor CNX 5000 didapatkan FBR sebesar $10 \mathrm{~dB}$.

Respon frekuensi antena hasil desain ditunjukkan pada gambar 7 . Respon frekuensi tidak flat diseluruh frekuensi uji dan level sinyal berada diatas $-55 \mathrm{~dB}$. Respon frekuensi terbaik didapatk pada antena CNX 5000, sedangkan pada antena indoor jaguar 125 respon frekuensi hampir sama dengan antena hasil desain.

Perbadingan gain antena dapat dilihat pada plot polaradiasi gabungan antena mikrostrip hasil desain dengan antena jaguar 125 dan CNX 5000 yang ditunjukkan pada gambar 8. Dimana pola daya maksimum untuk antena mikrostrip -29 dB, sedangkan antena CNX 5000 adalah $-27 \mathrm{~dB}$ dan antena jaguar $-34 \mathrm{~dB}$. Ini berarti antena mikrostrip hasil desain mempunyai gain yang mendekati antena outdoor cnx 5000 dan lebih baik dari antena indoor jaguar 125 .

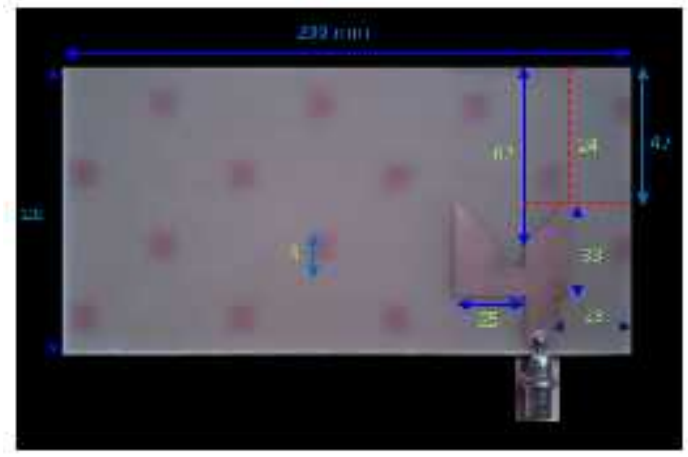

Gambar 5. Fabrikasi hasil desain antena mikrostrip bentuk angka 4 .
Polenatins Miliostrup Honzontal das Vertikal

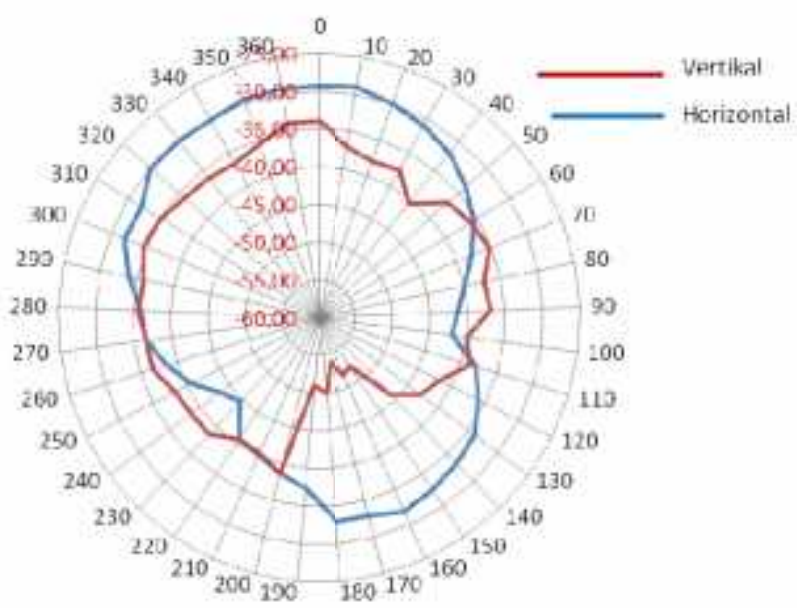

Gambar 6. Polaradiasi antenna mikrostrip hasil fabrikasi

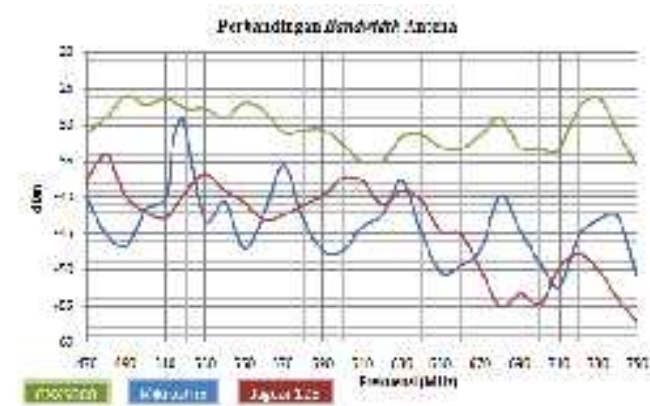

Gambar 7 Respon Frekuensi

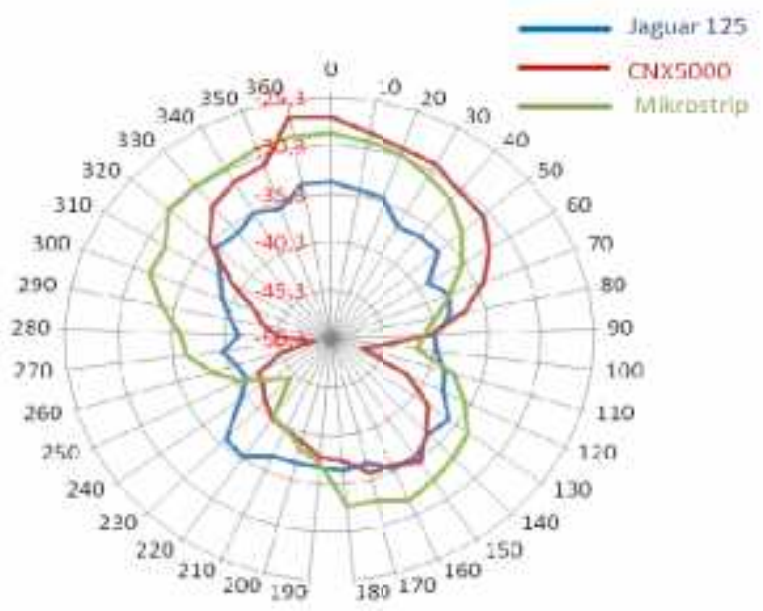

Gambar 8. Perbandingan Gain antena 


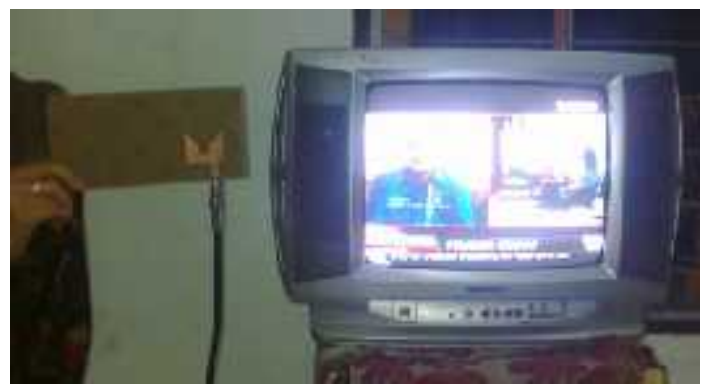

Gambar 9 Pengujian untuk penerimaan siaran TV

\section{KESIMPULAN}

Antena mikrostrip hasil desain menunjukkan kinerja yang cukup baik sebagai antenna penerima indoor. Pengujian pada siaran tv ditunjukkan pada gambar 9. Kekurangannya adalah polariadiasi lebih mendekati uni directional sehingga membutuhkan pengaturan posisi antenna untuk menerima sinyal frekuensi lain yang tidak berada pada level penerimaan maksimum antenna.

\section{DAFTAR PUSTAKA}

Constantin A Balanis, "Antenna Theory : Analysis and Design 3 rd Edition" John Wiley \& Sons Inc. 2005.

Behdad, Nader, Simulation of a $2.4 \mathrm{GHz}$ Patch Antenna Using IE3D, University of Central Florida, 2007.

https://www.google.com/search?q=spekt rum+frekuensi (diakses 30 Agustus 2013)

Yulindon, Firdaus, Buku Ajar " Teori dan Perencanaan Antena",teknik telekomunikasi Politeknik Negeri Padang, 2007 
ISSN :2085-6989 